\title{
¿Qué dice el Islam sobre María?*
}

\author{
Fanny Ochoa O. (Asiah)**
}

\section{Resumen}

en este artículo la autora, partiendo de la idea acentuada en nuestro contexto de que el Islam es la civilización y religión menos tolerante, reconoce que este estereotipo a veces ha impedido un acercamiento al diálogo, al conocimiento, al estudio y a la investigación con rigor académico, teológico y científico de un mundo aún nuevo y desconocido por gran parte de nuestros estudiosos. La autora parte de la premisa de que, para poder hacer un acercamiento a comprender el tema que trata (María en el Islam), se debe abordar brevemente qué plantea el Islam para que posteriormente los lectores puedan hacer un paralelo con lo que ven, leen y oyen, especialmente sobre la mujer en el Islam.

Palabras clave: María, madre de Jesús, Anunciación, Islam, Corán.

* Conferencia panel interreligioso del III Congreso Internacional de Teología Mariana de la Facultad de Teología de la Universidad Santo Tomás (Chiquinquirá, Boyacá), el 21 de septiembre de 2012.

** Comunicadora social y periodista por la Universidad Jorge Tadeo Lozano (Bogotá) y especialista en Opinión Pública por la misma universidad. Actualmente se desempeña como directora de investigaciones y coordinadora del Instituto Halal del Centro Cultural Islámico en Colombia. Correo electrónico: centroculturalislamico@gm.com 
La idea extendida de que el Islam es la civilización y religión menos tolerante está muy acentuada en nuestro medio. este estereotipo a veces ha impedido un acercamiento al diálogo, al conocimiento, al estudio y a la investigación con rigor académico, teológico y científico de un mundo aún nuevo y desconocido por gran parte de nuestros estudiosos. Por estas razones, para poder acercarnos a una comprensión y entendimiento del tema que nos reúne, debemos abordar brevemente qué plantea el Islam para que posteriormente ustedes puedan hacer un paralelo con lo que ven, leen y oyen, especialmente sobre la mujer en el Islam.

y para iniciar hay que hablar del concepto fundamental que sobre el Islam se tiene, al decir que es la religión del monoteísmo absoluto, que significa la creencia en la unidad de Dios. Él es uno en esencia. Él es el único creador. Él es el único que dirige el mundo. Solamente Él merece la adoración y veneración. Si es el único creador, tiene toda la soberanía sobre lo creado y sobre Él mismo.

Vuestro Dios es un Dios Uno. No hay más dios que Él, el Compasivo, el Misericordioso.

en la creación del cielo y de la tierra, en la sucesión de la noche y el día, en las naves que surcan el mar para provecho de los hombres, en el agua que Alá hace bajar del cielo, vivificando con ella la tierra después de muerta, diseminando por ella toda clase de bestias, en la variación de los vientos, en las nubes, sujetas entre el cielo y la tierra, hay, ciertamente, signos para los que razonan (Corán 2 [La vaca]: 163-164).

Bajo los principios anteriores, ¿quién es María (Mariam) en el Islam? es la mujer más venerada por los musulmanes, la única cuyo nombre es mencionado en el Corán. Los demás son personajes masculinos (Abraham, Noé, David, Jesús, etc.).

en cuanto a María, el Corán, en pasajes del Libro sagrado - que datan tanto del comienzo de la Revelación, que comenzó con la aparición del ángel san Gabriel al profeta Muhammad (Mahoma es español) en el año 610 d. C., así como de sus fases más tardías - se subraya su eminencia y perfección, lo mismo que las circunstancias que rodearon el nacimiento milagroso de su 
hijo, quien siempre es nombrado en el Corán como ‘Jesús hijo de María' ('Isa ibnMaryam.)

Como prueba fidedigna de la importancia de María en el Islam hay que subrayar el hecho de que la sura XIX del Corán, que relata la anunciación y la natividad de Jesús, se designa por su nombre: Mariam, o María en español.

Los autores musulmanes que frecuentemente se han interesado en la genealogía de la Virgen reconocen en general una ascendencia noble y la ven como parte del linaje de Aaron (Haroun), hermano de Moisés (Moussa). Con relación a sus padres y a su venida al mundo, cuentan un episodio que se ha hecho popular: su padre 'Imrân (Joaquín para los cristianos) y su madre Hanna (santa Ana), que llevaban una existencia modesta y tranquila en Nazaret, no habían tenido descendencia hasta una edad avanzada. Un día su atención se vio atraída por un pájaro que, en un árbol, daba alimento a sus crías. emocionada y bajo el efecto de un arrebato de amor maternal, Ana (Hanna) sintió el deseo de tener un hijo y de dedicarlo al servicio de Dios. Su deseo fue concedido. La historia de María se narra principalmente en dos suras: Corán 3 (Al Imran): 33-47 y la 19 (Mariam): 16-29 y en dos aleyas más: Corán 21:91 y Corán 66:12.

Según estudiosos de las religiones, la persona elegida por Dios es aquella que ha llegado a contradecir las costumbres de su tiempo y criticado lo que sucede en su sociedad. y es una persona que permanece alejada de la atracción de poder, de la tradición y de la opinión pública, y solo obedece a Dios, a Allah. estas cualidades las podemos encontrar en tres momentos de la vida de María (p): en su nacimiento y educación, el alejamiento en un lugar oculto en el templo y el enfrentamiento de su pueblo.

Para el Islam, Ana (Hanna) y Joaquín (Imran) oran por un hijo y Ana promete que si su oración es aceptada, dedicará su hijo al servicio de Dios, protegido de Satanás. el Corán relata que una vez nació María, la entregó a la protección y formación de zacarías, el profeta.

Corán 3:

(34) Cuando una mujer de [la Casa de] Imrán dijo: “ $\mathrm{OOh}$ Sustentador mío! Hago el voto de ofrecerte lo que hay en mi vientre, para que se dedique exclusivamente a Tu servicio. ¡Acéptamelo! ¡Ciertamente, Tú eres quien todo lo oye, quien todo lo sabe!" (35) Pero cuando dio a luz a una hija, dijo: “ $\mathrm{OOh}$ Sustentador mío! He dado a luz a una hembra y 
le he puesto por nombre María. e imploro Tu protección para ella y su descendencia contra Satán, el maldito". (36) y su Sustentador la aceptó favorablemente, la hizo crecer armoniosamente, y la confió a Zacarías.

María tiene una posición relevante en el Islam y Dios la coloca como la mejor de las mujeres de entre su creación. Para varios exegetas del Corán, ella es lo más cercano a un ser humano perfecto en todas sus dimensiones: espiritual, social, como madre e intelectual. y cuando el Corán narra que fue colocada bajo la protección del profeta zacarías, no podemos pasar por alto que en esa época el pueblo judío estaba esperando la venida del Salvador, del Mesías, y se hablaba de señales del tiempo que confirmarían la buena nueva; de esta manera, cada mujer de Judea esperaba ser la madre del esperado. Para el Islam, zacarías, hombre sabio de su tiempo y profeta, vio en Ana y Joaquín señales de que eran los elegidos y, seguro de esto, anunció a su pueblo la noticia.

\section{Corán 3:}

(35) Pero cuando dio a luz a una hija, dijo: “¡Oh Sustentador mío! He dado a luz a una hembra y le he puesto por nombre María. e imploro Tu protección para ella y su descendencia contra Satán, el maldito". (36) y su Sustentador la aceptó favorablemente, la hizo crecer armoniosamente, y la confió a Zacarías.

Pero como no era el varón esperado, la gente se burló de zacarías, quien pidió al Señor que lo guiara y le diera una señal: una revelación en la que Dios le pidió que protegiera y acogiera a María en su templo y de esta manera ayudar a Ana, que había quedado viuda, a cumplir la promesa hecha cuando engendró a María. Fue esta una decisión difícil, pues asistir y formarse en el templo era exclusivo de los hombres, no de una mujer. María permaneció en recogimiento y aislamiento total, y no sabemos si esto obedeció al hecho de que el profeta zacarías debió hacerlo así para evitar ser molestado y agredido por su pueblo, a causa de proteger a una mujer.

en la sura 3,37-38 se narra cómo María tenía la costumbre de retirarse en un mihrab, un nicho de oración, y cada vez que zacarías entraba allí, comprobaba que ella disponía de un alimento llegado misteriosamente. Él le preguntaba entonces: “¿Oh, María, de donde viene todo esto?”. ella respondía: 
“esto viene de Dios: Dios da su subsistencia a quién Él quiere”. Para algunos intérpretes del Corán, este alimento es el de la ciencia, del saber, otorgado a una mujer virtuosa que recibe la preparación para ser madre, educadora, líder y la guía del Mesías que ha de venir. es además una mujer que en el Corán tiene un estatus jurídico propio como sujeto individual de derecho, una mujer que tiene derechos espirituales, sociales, económicos y políticos dictados por Dios. Este versículo figura frecuentemente entre los motivos caligráficos que adornan los mihrabs de las mezquitas, particularmente en Turquía.

\section{Corán 19:}

(15) y recuerda, por medio de esta escritura divina, a María. He ahí que se retiró de su familia a un lugar en el este (16) y se recluyó apartada de ellos, y entonces le enviamos a Nuestro ángel de la revelación, que se apareció a ella en la forma perfecta de un ser humano. (17) ella exclamó: “¡en verdad, me refugio de ti en el Más Misericordioso! ¡[No te acerques a mí] si eres consciente de Él!" (18) [el ángel] respondió: "Soy solo un emisario de tu Sustentador, [quien dice,] 'Te concederé el regalo de un hijo puro'". (19) Ella dijo: “¿Cómo voy a tener un hijo si ningún hombre me ha tocado? - pues, no he sido una mujer licenciosa". (20) [El ángel] dijo: "Así ha de ser; [pues] tu Sustentador dice, 'Eso es fácil para Mí; y [tendrás un hijo,] para que hagamos de él un signo para la humanidad y una gracia venida de Nosotros', y era un asunto ya decretado [por Dios]".

\section{Corán 3:45}

He ahí, que los ángeles dijeron: “ $\mathrm{OOh}$, María! En verdad, Dios te anuncia la buena nueva, mediante una palabra procedente de Él, [de un hijo] que será conocido como el Ungido Jesús, hijo de María; de gran eminencia en este mundo y en la Otra Vida, y [será] de los allegados a Dios".

esto constituyó una gran prueba para María, ya que a pesar de que era conocida por su piedad, la acusaron de ser inmoral:

Y cuando los ángeles dijeron: “ ¡Oh, María! Allah te albricia con su palabra. Su nombre será El Mesías, Jesús hijo de María, será distinguido 
en esta vida y en la otra, y se contará entre los más próximos a Allah" (Corán 3:45-48).

Cuando las señales de su embarazo se hicieron evidentes, María temió por lo que la gente dijera de ella. La noticia se extendió rápido, y como era de suponerse, fue acusada de indecente. Para los cristianos María se casó con José; para el Islam ella no tenía marido, no fue desposada, y esta era la causa de las murmuraciones y de su angustia. La gente creyó que María había fornicado, entonces ella decidió alejarse a una tierra distante. Dios dice en el Corán: “Lo concibió, y decidió retirarse a un lugar apartado. Los dolores del parto la llevaron junto al tronco de una palmera" (Corán 19:22). enfrentó el dolor sola, alejada de su pueblo, de la gente que la rechaza. Pero que Dios la haya elegido y preparado es una insospechada revolución, que sea la madre del Mesías y que ella sea de condición humilde, en un lugar apartado y rodeada de violencia e intolerancia es otra revolución. es María más y mejor que una "sierva": es la pura adoradora totalmente consagrada a Dios.

Sea como sea, los musulmanes están de acuerdo en llamarla Sayyidatuna Maryam, cuya traducción exacta es "Nuestra Dama María". Así, ella es investida de una misión de reconciliación del mundo de acuerdo con este pasaje coránico: "Nosotros hemos hecho de ella y de su hijo un signo para los mundos".

y con el ejemplo de María, el mensaje del Corán se dirige a equilibrar el estatus de las mujeres y el reconocimiento de su igualdad con respecto al hombre. Porque el Corán dice: hombres y mujeres son iguales; solo los diferencia la piedad y el conocimiento. y para los musulmanes y las mujeres en general esta distinción es un punto esencial en el Corán; es la recuperación de la dignidad de la mujer. y María es y será una esencia femenina compatible con la esencia Divina; un rescate a la dignidad como ser humano y una confirmación de igualdad.

\section{Referencias}

Junta Islámica. (2001). El Corán. Abdurrasak Pérez (Trad.). Disponible en: http:// www.webislam.com/coran/. Consultado el 3 de septiembre de 2013. 
